\title{
Urgency of retinal detachment repair: is it time to re-think our priorities?
}

\author{
Anna Grabowska $\mathbb{D}^{1} \cdot$ James E. Neffendorf ${ }^{2} \cdot$ David Yorston $\mathbb{D}^{3} \cdot$ Tom H. Williamson $\mathbb{B}^{2}$
}

Received: 16 July 2020 / Revised: 13 August 2020 / Accepted: 17 August 2020 / Published online: 1 September 2020

(c) The Royal College of Ophthalmologists 2020

Traditionally, the timing of rhegmatogenous retinal detachment $(\mathrm{RRD})$ repair has been dependent on a binary assessment - whether the macula is detached or not. The rationale for this was based on the opinion that permanent functional damage occurred once the macula had detached, and therefore surgery should be performed within $24 \mathrm{~h}$ for a macula-on detachment [1, 2]. Patients presenting with a macula-off detachment have therefore been considered lower priority. Yorston et al. have recently reignited the debate on timing of surgery with their work on the effect of duration of macular detachment on visual recovery [3]. Although it continues to be standard practice to differentiate between macula-on (foveaon) and macula-off (fovea-off) detachment, it would be valuable to identify factors indicating a high risk of rapid progression of a macula-on RRD. The question we address here is whether the pre-operative status of the macula is still the most important factor determining the urgency of RRD repair.

In 1982, Burton reported visual outcome after RRD repair was generally dependent on the duration of macular involvement. He found patients with macular detachment of $\leq 9$ days duration were significantly more likely to regain a final vision of $6 / 15$ or better than those with macula detachment of 10-19 days, or $\geq 20$ days $(p<0.05)$ [1]. Later, Ross and Kozy reported equal visual outcomes whether RRD repair occurred 1-2 days, 3-4 days or 5-7 days after macular detachment [4]. Both of these studies were based on scleral buckling. This led to a policy of treating macula-off RRD with less urgency. However, several recent studies have yielded different

Tom H. Williamson

tom@ retinasurgery.co.uk

King's College Hospital, London, UK

2 St. Thomas' Hospital, London, UK

3 Gartnavel Hospital, Glasgow, UK results [5]. Williamson et al. examined 325 macula-off RRD patients with primary success and no proliferative vitreoretinopathy. They showed that final vision was significantly better if the retina was reattached 1-3 days after loss of vision compared to 4-6 days [6]. These findings were echoed by Yorston et al. in their UK database study of over 2000 eyes with macula-off RRD [3]. The most important modifiable risk factor to achieve better visual results was the duration of central visual loss (i.e. foveal detachment) being less than $72 \mathrm{~h}$.

It is also important to note that the difference in visual outcome between macula-on and macula-off RRD of less than $72 \mathrm{~h}$ is minimal, since those with macula involvement still achieve good (median 6/9) visual outcomes [6]. Furthermore, the risk of pre-operative conversion from maculaon at presentation to macula-off detachment has been shown to be low $(0.5-0.11 \%)$ when surgery is performed within $24 \mathrm{~h}$. The majority of cases that progress, occur within a few hours and have good visual outcomes [7]. The comparison of RRD displacement velocity during posturing and interruptions showed that superior RRD patient could benefit from pre-operative posturing [8].

In addition, intraoperative progression of macula-on RRD and macular displacement (as shown by autofluorescence vessel shift) after pars plana vitrectomy with gas can occur, and may be more common than is currently recognised [9]. If the $\mathrm{RRD}$ is liable to convert from maculaon to macula-off during surgery, it is questionable that preoperative foveal attachment should be the main determinant of surgical prioritisation.

A careful assessment of RRD characteristics at presentation is important to determine the speed of RRD progression. In Kontos' study assessing change in macular status between diagnosis and surgery, 10/930 patients progressed from macula-on to macula-off $\mathrm{RRD}$, and the majority (9/10) had superotemporal detached retinal breaks. Only one case had superonasal RRD resulting in macula-off RRD. All ten patients regained 6/12 or better vision and only one patient reported some distortion [7]. Another study 
of 82 patients found subretinal fluid progressed towards the fovea in $13 \%(11 / 82)$ usually when associated with a superior RRD $(73 \%, 8 / 11)$, and superior retinal breaks $(64 \%, 7 / 11)$ at a rate of 1.80 disc diameters per day [10]. Whilst the risk of pre-operative progression to macula-off is low, early surgical repair can still be encouraged, because post-operative symptoms such as distortion and micropsia may be more likely when the fovea detaches [11, 12]. These studies indicate that the pattern and clinical features of RRD can help identify those at the highest risk of progression.

An electronic medical record retrospective database study of 847 patients found $69 \%$ of RRDs had superotemporal breaks, the majority of which were present in detached retina (92\%) [6]. Conversely, 17\% had inferonasal breaks, which were more likely to be attached (40\%). These findings suggest that RRD has a tendency to commence superotemporally and 'recruits' flat breaks as it spreads inferiorly around the fundus. The break position is important: superotemporal breaks are associated with anatomical success, and detached inferior breaks with failure [6]. By association therefore, RRD repair is time dependent as detached inferior breaks and the totality of detached retina reduce primary success rates, irrespective of macular status. Primary surgical success is a major factor in achieving a good visual outcome [12, 13].

The timing of surgery is a substantial issue in patients with RRD. Macular status is clearly important, but it would appear that the paradigm of 'within $24 \mathrm{~h}$ ' surgery for macula-on cases, and 'as soon as convenient' for recent macula-off cases requires modification. Patients with macula-off RRD at presentation of short duration $(\leq 72 \mathrm{~h})$ achieve only marginally worse visual acuity outcomes than patients with macula-on, and therefore those with recent macula involvement (1-3 days) ought to have their surgery prioritised. Superotemporal RRDs extending to the retinal arcades are at the greatest risk of progression to macula-off but have the highest primary success rate. These detachments require early surgery and pre-operative posturing to limit progression to totality and the recruitment of inferior breaks. Given that many macula-on RRDs are at low risk of progression to macula-off, an evidence based prioritisation could treat superotemporal macula-on RRD as most urgent, followed by recent (1-3 days) macula-off RRD, followed by other macula-on RRD.

\section{Compliance with ethical standards}

Conflict of interest The authors declare that they have no conflict of interest.

Publisher's note Springer Nature remains neutral with regard to jurisdictional claims in published maps and institutional affiliations.

\section{References}

1. Burton TC. Recovery of visual acuity after retinal detachment involving the macula. Trans Am Ophthalmol Soc. 1982;80: 475-97.

2. Ross WH. Visual recovery after macula-off retinal detachment. Eye. 2002;16:440-6.

3. Yorston D, Donachie PHJ, Laidlaw DA, Steel DH, Sparrow JM, Aylward GW, et al. Factors affecting visual recovery after successful repair of macula-off retinal detachments: findings from a large prospective UK cohort study. Eye. e-pub ahead of print https://doi.org/10.1038/s41433-020-1021-y 2020.

4. Ross WH, Kozy DW. Visual recovery in macula-off rhegmatogenous retinal detachments. Ophthalmology. 1998;105:2149-53.

5. van Bussel EM, van der Valk R, Bijlsma WR, La Heij EC. Impact of duration of macula-off retinal detachment on visual outcome: a systematic review and meta-analysis of literature. Retina. 2014;34: 1917-25.

6. Williamson TH, Lee EJ, Shunmugam M. Characteristics of rhegmatogenous retinal detachment and their relationship to success rates of surgery. Retina. 2014;34:1421-7.

7. Kontos A, Williamson TH. Rate and risk factors for the conversion of fovea-on to fovea-off rhegmatogenous retinal detachment while awaiting surgery. Br J Ophthalmol. 2017;101:1011-5.

8. de Jong JH, Vigueras-Guillen JP, Simon TC, Timman R, Peto T, Vermeer KA, et al. Preoperative posturing of patients with macula-on retinal detachment reduces progression toward the fovea. Ophthalmology. 2017;124:1510-22.

9. Lee E, Williamson TH, Hysi P, Shunmugam M, Dogramaci M, Wong R, et al. Macular displacement following rhegmatogenous retinal detachment repair. Br J Ophthalmol. 2013;97:1297-302.

10. Ho SF, Fitt A, Frimpong-Ansah K, Benson MT. The management of primary rhegmatogenous retinal detachment not involving the fovea. Eye. 2006;20:1049-53.

11. Ugarte M, Williamson TH. Horizontal and vertical micropsia following macula-off rhegmatogenous retinal-detachment surgical repair. Graefes Arch Clin Exp Ophthalmol. 2006;244:1545-8.

12. Williamson TH, Shunmugam M, Rodrigues I, Dogramaci M, Lee E. Characteristics of rhegmatogenous retinal detachment and their relationship to visual outcome. Eye. 2013;27:1063-9.

13. Lee E, El Housseini Z, Steel DH, Williamson TH. An analysis of the outcomes for patients with failed primary vitrectomy for rhegmatogenous retinal detachment. Graefes Arch Clin Exp Ophthalmol. 2014;252:1711-6. 